\title{
Gas Chromatography-Mass Spectrometric Determination of Fatty Acids in Seed Oil of Winged Bean (Psophocarpus tetragonolobus (L.) DC) ${ }^{1}$
}

\author{
Masako HiguchI, ${ }^{2}$ Junji TeraO, ${ }^{3}$ and Kazuo IWAI ${ }^{2}$ \\ ${ }^{2}$ Department of Food Science and Technology, \\ Faculty of Agriculture, Kyoto University \\ Kitashirakawa, Sakyo-ku, Kyoto 606, Japan \\ ${ }^{3}$ Research Institute for Food Science, Kyoto \\ University, Uji, Kyoto 611, Japan \\ (Received March 12, 1982)
}

\begin{abstract}
Summary Fatty acids of winged bean seed oil were examined by gas chromatography-mass spectrometry of their pyrrolidide derivatives. Oleic and linoleic acids were determined to be the major unsaturated fatty acids in the oil. Long chain saturated fatty acids, such as behenic and lignoceric acids, were found in relatively high amounts as compared with other edible seed oils. The fatty acids that could not be separated by gas liquid chromatography were identified as linolenic acid and arachidic acid respectively on mass spectrometric analysis. Parinaric acid, previously reported by Cerny et al., was not detected and this supposed fraction was instead found to be eicosenoic acid. Erucic acid, suspected of having an adverse effect on myocardial lesions in rats, was detected but only in small quantity. The identifications of these unsaturated fatty acids were further confirmed by deducing the location of the double bonds in their moieties. From these findings, winged bean seed oil can be suggested as being a food source of favorable quality.
\end{abstract}

Key Words winged bean seed oil, fatty acids, pyrrolidide derivatives, GC-MS analysis

Winged bean (Psophocarpus tetragonolobus (L.) DC), indigenous to the humid tropics, has been widely cultivated in Southeast Asia and other areas for centuries. All parts of this plant are said to be edible, i.e. seeds, green pods, flowers, shoots and tubers; especially, young green pods are the most popular edible part of the plant.

1 Presented at the 35th General Meeting of the Japanese Society of Nutrition and Food Science, Tokushima, Japan, May 28, 1981.

2 樋口雅子, ${ }^{3}$ 寺尾純二, ${ }^{2}$ 岩井和夫

Abbreviations: GC-MS, gas chromatography-mass spectrometry; GLC, gas liquid chromatography; MC, mass chromatography; amu, atomic mass units. 
Recently, the ripe seed has been brought to attention as constituting a promising legume in the tropics due to its agricultural and nutritional potential. Several studies have indicated the favorable nature of the seed as food, which is rich in protein and fat $(1-3)$. However, concerning the constituent fatty acids of the seed oil, conflicting evaluations have been made from an analysis using $\operatorname{GLC}(2,4,5)$, particularly as to whether unusual fatty acid is present or not. Cerny et al.(2) first suspected the presence of an unusual fatty acid in the winged bean seed, and tentatively identified it as parinaric acid (octadecatetraenoic acid) on the basis of relative retention time. On the other hand, Ekpenyong and Borchers (4) suggested that this fatty acid could be eicosenoic acid, by plotting the log of retention times against carbon number. Parinaric acid, which is reported to be toxic (4), was first isolated from the oil of kernels of Parinarium laurinum (6), but it has not been found in any edible legume seed.

With respect to mass spectrometric analysis of fatty acids, Vetter et al. (7) and Andersson et al. (8) demonstrated that the pyrrolidide derivatives of unsaturated fatty acids give mass spectra which indicate exactly the location of the double bonds.

This paper deals with the determination of the fatty acid composition of winged bean seed oil by GC-MS of their pyrrolidide derivatives.

\section{MATERIALS AND METHODS}

Material. Ripe seeds of winged bean were obtained from Malaysia. After having been dried at $40^{\circ} \mathrm{C}$ for 2 days, the seeds were ground by Retsch cyclone mill to pass through a 32-mesh sieve.

Analytical methods. Crude protein, crude fat, acid detergent fiber, ash and moisture were determined by standard methods of analysis (9). Carbohydrate was determined as being reducing sugar by the phenol- $\mathrm{H}_{2} \mathrm{SO}_{4}$ method (10) using glucose as a standard sugar.

Sample preparation. Oil of the winged bean seed was extracted with chloroform-methanol $(2: 1, \mathrm{v} / \mathrm{v})$, and was converted into methyl ester using $5 \% \mathrm{HCl}$ in methanol at $100^{\circ} \mathrm{C}$ for $3 \mathrm{hr}$ in a sealed tube.

The pyrrolidide was prepared from the methyl ester by the procedure of Andersson and Holman (11). About $10 \mathrm{mg}$ of fatty acid methyl ester was dissolved in $1 \mathrm{ml}$ of pyrrolidine and $0.1 \mathrm{ml}$ of acetic acid, and heated at $100^{\circ} \mathrm{C}$ in a sealed tube for $30 \mathrm{~min}$. The mixture cooled to room temperature was taken up in methylene chloride and washed with dilute $\mathrm{HCl}$ and water. After having been dried with magnesium sulfate and evaporated under a stream of nitrogen gas, the pyrrolidide was dissolved in $n$-hexane to make a sample for GC-MS.

Gas liquid chromatography. A Shimadzu GC-6AM gas chromatograph was used with a flame ionization detector (FID). A $2 \mathrm{~m} \times 3 \mathrm{~mm}$ I.D. stainless steel column was packed with $10 \%$ ethylene glycol succinate siloxane (EGSS-X) on 60-80 mesh Chromosorb W, and the column temperature was programmed from $160^{\circ}$ to 
$210^{\circ} \mathrm{C}$ at $3^{\circ} \mathrm{C} / \mathrm{min}$. Nitrogen carrier gas was used at a flow rate of $50 \mathrm{ml} / \mathrm{min}$.

Gas chromatograph peaks were identified by comparison with authentic fatty acids with respect to retention times. The area under the individual peak was determined by an integrator (Shimadzu Chromatopac-E1A). All chemicals were of reagent grade, purchased from Nakarai Chemical Co.

Gas chromatography-mass spectrometry. The gas chromatograph-mass spectrometer, Shimadzu-LKB 9000, was combined with a MS-PAC 300 DGB computer system. The separation column $(2 \mathrm{~m} \times 3 \mathrm{~mm}$ I.D. $)$ was packed with $10 \%$ Silar $10 \mathrm{C}$ on 60-80 mesh Chromosorb W. Helium was used at $30 \mathrm{ml} / \mathrm{min}$. The column temperature was varied from $160^{\circ}$ to $260^{\circ} \mathrm{C}$ at $4{ }^{\circ} \mathrm{C} / \mathrm{min}$, the molecular separator temperature being set at $290^{\circ} \mathrm{C}$ and the ion source temperature at $310^{\circ} \mathrm{C}$. The ionizing electron energy was set at $22 \mathrm{eV}$. The selected ion retrieval was performed from respective scans obtained at 10 -sec intervals.

\section{RESULTS}

\section{Proximate composition of winged bean seed}

The proximate composition of winged bean seed is shown in Table 1. Crude fat, extracted by ether, and crude protein, amounted to $20.3 \%$ and $32.2 \%$, respectively.

\section{GLC of the fatty acid methyl esters in winged bean seed oil}

Figure 1 shows the gas chromatogram. Lauric, myristic, palmitic, stearic, oleic, linoleic, behenic and lignoceric acids were clearly identified in comparison with the retention times of authentic fatty acid methyl esters. Under the conditions employed, linolenic and arachidic acids were eluted together as one peak (peak 7 in Fig. 1). Parinaric and eicosenoic acids may also have been eluted with an identical retention time (peak 8 in Fig. 1).

MC of the pyrrolidide derivatives of the fatty acids in the seed oil

In order to identify the fatty acids unseparated by GLC, the pyrrolidide derivatives, converted from methyl esters, were applied to GC-MS. Figure 2 shows the mass chromatogram of the pyrrolidides of the long chain fatty acids in winged bean seed oil, i.e. linolenic, parinaric, arachidic, eicosenoic, behenic, erucic and

Table 1. Proximate composition of winged bean seed.

$\begin{array}{lc}\text { Protein }(\text { Kjeldahl N } \times 6.25) & 32.2 \% \\ \text { Carbohydrate }\left(\text { Phenol- } \mathrm{H}_{2} \mathrm{SO}_{4} \text { method) }\right. & 21.1 \\ \text { Fat (Soxhlet extract) } & 20.3 \\ \text { Fiber (Acid detergent) } & 13.8 \\ \text { Ash (Incineration) } & 4.0 \\ \left.\text { Moisture (Drying, } 105^{\circ} \mathrm{C}\right) & 8.6\end{array}$




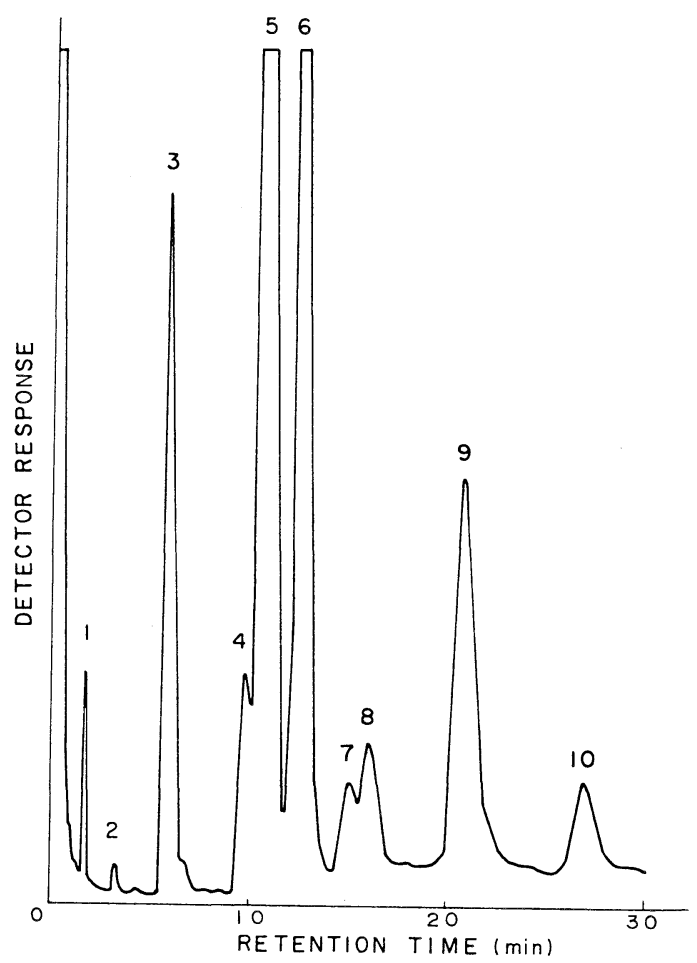

Fig. 1. Gas chromatogram of fatty acid methyl esters on $10 \%$ EGSS-X column. Column temperature was programmed from $160-210^{\circ} \mathrm{C}$ at $3^{\circ} \mathrm{C} / \mathrm{min}$. Peaks: 1 , lauric acid; 2, myristic acid; 3, palmitic acid; 4, stearic acid; 5, oleic acid; 6 , linoleic acid; 7 \& 8, not identified; 9 , behenic acid; 10 , lignoceric acid.

lignoceric acids. A mass chromatogram is obtained by monitoring molecular ions using computer data system. MC for $m / z 329$ obviously indicated that parinaric acid was not present in the seed oil, and proved that the peak obtained earlier with GLC was only due to the occurrence of eicosenoic acid $(m / z$ 363). Both linolenic acid and arachidic acid were detected from MC for $m / z 331$ and 365, respectively. Erucic acid (docosaenoic acid) was also detected from MC for $m / z$ 391. These identifications were further confirmed by each mass spectrum. An example of the mass spectrum of the pyrrolidide of a fatty acid is presented in Fig. 3. Intense molecular ion, $m / z 363$, indicates that the pyrrolidide is of eicosenoic acid. In all the spectra of the pyrrolidides, the base peak is formed by McLafferty rearrangement always at $\mathrm{m} / \mathrm{z}$ $113(12)$. This is followed by $m / z 126\left(\mathrm{C}_{3}\right), 140\left(\mathrm{C}_{4}\right), 154\left(\mathrm{C}_{5}\right), 168\left(\mathrm{C}_{6}\right), 182\left(\mathrm{C}_{7}\right)$, $196\left(\mathrm{C}_{8}\right)$, and $210\left(\mathrm{C}_{9}\right)$; these intervals were $14 \mathrm{amu}$. The most intense peak of the next cluster occurred at $m / z 222\left(\mathrm{C}_{10}\right)$, the interval between $\mathrm{C}_{9}$ and $\mathrm{C}_{10}$ was $12 \mathrm{amu}$. The rule for interpreting mass spectra of fatty acids pyrrolidides was formulated by Andersson and Holman (11): If an interval of $12 \mathrm{amu}$, instead of a regular $14 \mathrm{amu}$, is 
SAMPLE, DATE : PYR $-100 / 30 \mathrm{M} / \mathrm{HIGUCHI} / \mathrm{B} 10113$

R. T. (MIN) : 10.00

INTERVAL (SEC) : 10.00

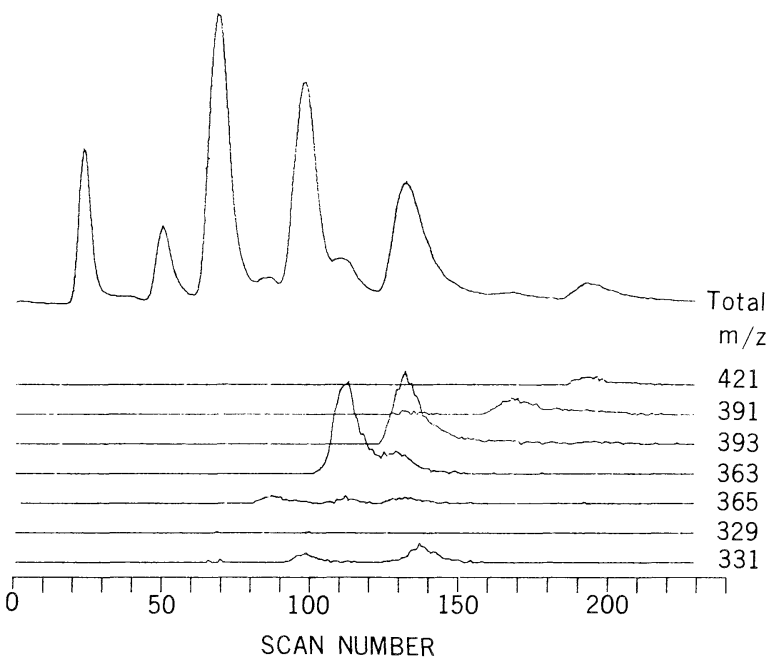

Fig. 2. Mass chromatogram of pyrrolidides derived from fatty acid methyl esters. GCMS was carried out on a Shimadzu-LKB 9000 instrument equipped with a MS-PAC 300 DGB computer system using $10 \%$ Silar $10 \mathrm{C}$ on a Chromosorb W column. Total = chromatogram obtained by monitoring total ions with total ion collector. The molecular ions for pyrrolidides were selected for MC as follows; $m / z 331=$ linolenic acid, $m / z \quad 329=$ parinaric acid, $m / z \quad 365=$ arachidic acid, $m / z \quad 363=$ eicosenoic acid, $m / z \quad 393=$ behenic acid, $m / z \quad 391=$ erucic acid, $m / z \quad 421=$ lignoceric acid.

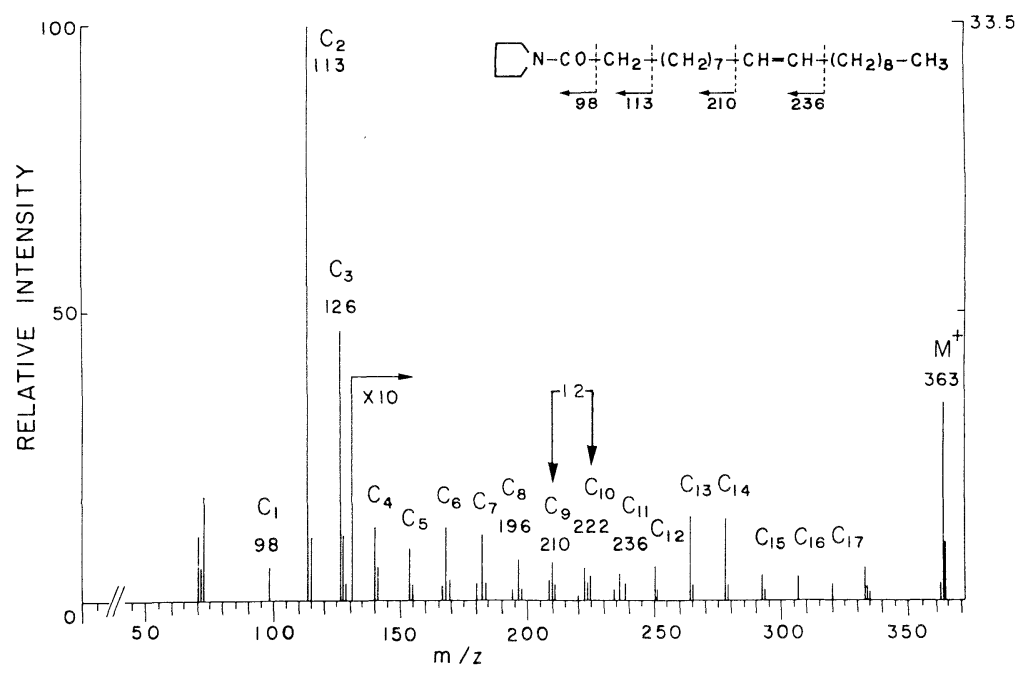

Fig. 3. Mass spectrum of eicosa-10-enoylpyrrolidine. Analytical conditions are the same as in Fig. 2.

Vol. 28, No. 5, 1982 
observed between the most intense peaks of clusters of fragments containing $n$ and $n-1$ carbon atoms, the double bond occurs between carbon $n$ and $n+1$ in the molecule. This rule has been confirmed for the pyrrolidide derivatives of monounsaturated fatty acid having 10-24 carbon atoms (11) and for those of polyunsaturated fatty acids (13). Under this rule the interval of amu between $\mathrm{C}_{9}$ and $\mathrm{C}_{10}$ was interpreted to indicate a double bond occurring between $C_{10}$ and $C_{11}$ (Fig. 3). The positions of the double bonds in other pyrrolidides were deduced by the same rule. The identifications are shown in Table 2. The location of double bonds in linolenic acid was not deduced, because from its mass spectrum it was hard to confirm whether the intervals of amu were 12 or 14 .

Fatty acid composition of winged bean seed oil

The fatty acid composition is presented in Table 2. Oleic and linoleic acids were the major unsaturated fatty acids present in the seed oil.

\section{DISCUSSION}

The proximate composition (Table 1) suggested that the winged bean seed was sufficiently rich in protein and fat, which made it comparable to other legume seeds such as soybean.

From MC the fatty acids unseparated by GLC were identified as linolenic and arachidic acids; the absence of parinaric acid was exactly determined, and this fraction was identified as eicosenoic acid.

Table 2. Fatty acid composition of winged bean seed oil.

The amounts of fatty acids were expressed as the ratio of each peak area to the total area on the gas chromatogram, while those of gas-chromatographically unidentified fatty acids were determined by mass chromatography.

\begin{tabular}{llr}
\hline Fatty acid & Identity & $\%$ \\
\hline Lauric & $12: 0$ & 0.9 \\
Myristic & $14: 0$ & 0.1 \\
Palmitic & $16: 0$ & 10.4 \\
Palmitoleic & $\Delta 9-16: 1$ & 0.6 \\
Stearic & $18: 0$ & 4.3 \\
Oleic & $\Delta 9-18: 1$ & 33.7 \\
Linoleic & $\Delta 9,12-18: 2$ & 29.0 \\
Linolenic & $18: 3$ & 2.1 \\
Arachidic & $20: 0$ & 1.1 \\
Eicosenoic & $\Delta 10-20: 1$ & 3.1 \\
Behenic & $22: 0$ & 11.3 \\
Erucic & $\Delta 13-22: 1$ & 0.9 \\
Lignoceric & $24: 0$ & 2.5 \\
\hline
\end{tabular}


Regarding the profile of fatty acids in the seed oil, the long chain saturated fatty acids such as behenic and lignoceric acids are contained in relatively high amounts (Table 2); these fatty acids have been scarcely detected in usual seed oils, while a small amount has been found in peanut and mustard oils. In addition, the winged bean contains more oleic than linoleic acids; it is more similar to peanut oil than to soybean oil.

In recent years, researches on fat metabolism have come to suggest some possible adverse effects of erucic acid in the diet (14-16). However, when rats were fed on a diet containing $9.2 \mathrm{Cal} \%$ erucic acid for 2 weeks, only minor fatty infiltration of the heart and skeletal muscles was observed (15). Erucic acid having no significant influence was also reported in myocardial lesions when rats were fed for 16 weeks on commercial lard to which $5.4 \%$ erucic acid was added (16). Erucic acid in winged bean seed oil was found only at a level of $0.9 \%$. This level is not adverse. From these results, winged bean seed oil can be suggested as being a good sources of edible oil.

We are grateful to Dr. S. Matsushita, Professor of Research Institute for Food Science, Kyoto University, for his assistance and suggestions in GC-MS analysis. We also thank Dr. K. Mori, Nippon Shinyaku Co., Ltd., and Mr. H. Kobayashi, K. Kobayashi \& Co., Ltd., for providing winged beans.

\section{REFERENCES}

1) Okezie, B. O., and Martin, F. W. (1980): Chemical composition of dry seeds and fresh leaves of winged bean varieties grown in the U.S. and Puerto Rico. J. Food Sci., 45, $1045-1051$.

2) Cerny, K., Kordylas, M., Pospisil, F., Svabensky, O., and Zajic, B. (1971): Nutritive value of the winged bean (Psophocarpus palustris Desv.). Br. J. Nutr., 26, 293-299.

3) Pospisil, F., Karikari, S. K., and Boaman-Mensah, E. (1971): Investigations of winged bean in Ghana. World Crops, September/October, 260-264.

4) Ekpenyong, T. E., and Borchers, R. L. (1980): The fatty acid composition of the oil of the winged bean (Psophocarpus tetragonolobus L.) seeds. J. Am. Oil Chem. Soc., May, 147-149.

5) Garcia, V. V., and Palmer, J. K. (1980): Fatty acid composition of the oil of winged beans, Psophocarpus tetragonolobus (L.) DC. J. Am. Oil Chem. Soc., 56, 931-932.

6) Farmer, E. H., and Sunderland, E. (1965): Unsaturated acids of natural oils. Part II. The highly unsaturated acid of the kernels of Parinarium laurinum. J. Chem. Soc. (London), Part I, 759-761.

7) Vetter, W., Walther, W., und Vecchi, M. (1971): Pyrrolidide als derivate fur die strukturaufkarung aliphatischer und alicyclischer carbonsauren mittels massenspektrometrie. Helv. Chim. Acta, 54, 1559-1605.

8) Andersson, B. A., Heimermann, W. H., and Holman, R. T. (1974): Comparison of pyrrolidides with other amides for mass spectral determination of structure of unsaturated fatty acids. Lipids, 9, 443-449.

9) Official Methods of Analysis of the Association of Official Analytical Chemists, 13th Ed. Washington DC, 1980. 
10) Dubois, M., Gilles, K. A., Hamilton, J. K., Reneers, P. A., and Smith, F. (1956): Colorimetric method for determination of sugars and related substances. Anal. Chem., 28, 350-356.

11) Andersson, B. A., and Holman, R. T. (1974): Pyrrolidides for mass spectrometric determination of the position of the double bond in monounsaturated fatty acids. Lipids, 9, 185-190.

12) Duffield, A. M., and Djerassi, C. (1965): Mass spectrometry in structural and stereochemical problems. LXXIV. A study of the fragmentation of $\mathrm{N}$-acylpyrrolidines. J. Am. Chem. Soc., 87, 4554-4559.

13) Andersson, B. A., Christie, W. W., and Holman, R. T. (1975): Mass spectrometric determination of positions of double bonds in polyunsaturated fatty acid pyrrolidides. Lipids, 10, 215-219.

14) Yasuda, S., Kitagawa, Y., Sugimoto, E., and Kito, M. (1980): Effect of erucic acid on phospholipid molecular species compositions of the rat heart and liver. J. Biochem., 87, 1511-1517.

15) Abdellatif, A. M. M., and Vles, R. O. (1970): Pathological effects of dietary rapeseed oil in rats. Nutr. Metab., 12, 285-295.

16) Hulan, H. W., Kramer, J. K. G., Mahadevan, S., and Sauer, F. D. (1976): Relationship between erucic acid and myocardial changes in male rats. Lipids, 11, 9-15. 